\title{
Panorama das Publicações Nacionais Sobre Acidentes com Perfurocortantes Associado a Exposição a Material Biológico
}

\author{
Overview of National Publications on Accidents with Cutting and Piercing Objects \\ Associated to Exposure to Biological Material
}

\author{
Victor Hugo Macedo Gomes ${ }^{1} *$ Magda Guimarães de Araújo Faria ${ }^{2}$ Delson da Silva ${ }^{3}$ Cristiane \\ Helena Gallasch ${ }^{*}$ Eugênio Fuentes Perez Junior ${ }^{5}$ Donizete Vago Daher ${ }^{6}$
}

RESUMO

O objetivo é relacionar o manuseio e o descarte de material perfurocortante com os acidentes com material biológico, de acordo com a literatura científica nacional. Pesquisa qualitativa do tipo revisão integrativa, com realização de análise de conteúdo. A partir da análise de 27 artigos, emergiram as seguintes unidades de significação: o descarte inadequado $(46 \%)$, inadequação do ambiente $(43 \%)$, imprudência (43\%), reencape e desconexão de agulha manualmente $(32 \%)$, manipulação de risco (29\%) e falta de treinamento (43\%). Estas foram agrupadas e analisadas nas categorias "Processos de trabalho inadequados" e "Ausência de capacitação técnica dos funcionários". Conclui-se que há fatores relacionados ao trabalhador, ao processo de trabalho e à própria instituição em que atuam, tanto isoladamente como articulados entre si, influenciando significativamente a exposição do trabalhador às situações de risco de contaminação por material biológico, sobretudo associado ao manuseio de instrumentos perfurocortante.

Palavras-chaves: Exposição Ocupacional; Exposição a Agentes Biológicos; Pessoal de Saúde.

\section{ABSTRACT}

Objective to relate the handling and disposal of sharp and piercing objects with accidents with biological material, according to national scientific literature. Method: Qualitative research of type integrative review, with content analysis. Results: The following units of significance emerged from the analysis of 27 articles: inadequate disposal (46\%), inadequate environment (43\%), recklessness (43\%), manually recapping and disconnecting the needle (32\%), risky handling (29\%) and lack of training (43\%). These were grouped and analyzed under the categories "Inadequate work processes" and "Absence of technical training of employees".

Conclusion: It is concluded that there are factors related to the worker, the work process and the institution in which they operate, both individually and not, significantly influencing the worker's exposure to risk of contamination by biological material, especially associated with handling sharp instruments.

Keywords: Occupational Exposure, Exposure to Biological Agents, Health Professionals

${ }^{1}$ Enfermeiro. Residente de enfermagem do trabalho do programa de especialização em enfermagem da Faculdade de Enfermagem da Universidade do Estado do Rio de Janeiro. E-mail: victohmg93@gmail.com

2Doutora em Enfermagem. Professora Adjunta do Departamento de Enfermagem em Saúde Pública da Faculdade de Enfermagem da Universidade do Estado do Rio de Janeiro. E-mail: magda.faria@live.com

${ }^{3}$ Mestre em Saúde Pública. Professor Assistente do Departamento de Enfermagem em Saúde Pública da Faculdade de Enfermagem da Universidade do Estado do Rio de Janeiro. E-mail: delsonsil@gmail.com

${ }^{4}$ Doutora em Enfermagem. Professora Adjunta do Departamento de Enfermagem Médico-Cirúrgico da Faculdade de Enfermagem da Universidade do Estado do Rio de Janeiro. E-mail: cristiane.gallasch@gmail.com

${ }^{5}$ Mestre em Enfermagem. Professor Assistente do Departamento de Enfermagem Médico-Cirúrgico da Faculdade de Enfermagem da Universidade do Estado do Rio de Janeiro. E-mail: eugenioperezjunior@gmail.com

${ }^{6}$ Doutora em Enfermagem. Professora Associada da Escola de Enfermagem Aurora de Afonso Costa da Universidade Federal Fluminense. Email: donizete@predialnet.com.br 


\section{INTRODUÇÃO}

Os Resíduos de Serviço de Saúde (RSS) são geradores de alto impacto ambiental causado pelo manejo e destinação inadequados, relacionando-se a contaminações, altos índices de infecção hospitalar e, até mesmo, epidemias, em função das contaminações dos lençóis freáticos ${ }^{(1)}$. Isso demonstra a importância da elaboração, a implementação e o desenvolvimento do Programa de Gestão de Resíduos de Serviços de Saúde (PGRSS).

Entende-se o gerenciamento dos resíduos em saúde (RSS) como um conjunto de procedimentos de gestão planejados e implementados a partir de bases científicas e técnicas, normativas e legais, com o objetivo de minimizar a produção de resíduos e proporcionar aos restos gerados um encaminhamento seguro de forma eficaz, buscando a proteção dos trabalhadores, a preservação da saúde pública, dos recursos naturais e do meio ambiente ${ }^{(2)}$.

Neste sentido, percebe-se que a rotina de trabalho em estabelecimentos de saúde exige que o trabalhador esteja atento às normas de biossegurança para garantir a proteção da sua saúde, sobretudo durante a manipulação de objetos perfurocortantes, nos quais se fazem necessárias precauções no manuseio e descarte destes dispositivos ${ }^{(3)}$.

Segundo o Ministério da Saúde ${ }^{(4)}$, entre as recomendações específicas que devem ser seguidas durante a realização de procedimentos que envolvam a manipulação de material perfurocortante, destaca-se a importância de ter a máxima atenção durante a realização dos procedimentos, jamais utilizar os dedos como anteparo durante a realização de procedimentos que envolvam materiais perfurocortantes, não reencapar, entortar, quebrar agulhas ou retira-las das da seringa com as mãos. Todo material perfurocortante (agulhas, scalp, lâminas de bisturi, vidrarias, entre outros), mesmo que estéril, deve ser desprezado em recipientes resistentes à perfuração e com tampas. Coletores específicos para descarte de material perfurocortante não devem ser preenchidos acima do limite de $2 / 3$ de sua capacidade total e devem ser colocados sempre próximos do local onde é realizado o procedimento.

O estudo se justifica pela importância da disseminação da informação sobre a exposição a material biológico a partir do manuseio e descarte inadequado de resíduos, sobretudo relacionado ao perfurocortante. $O$ descarte adequado de perfurocortantes deve ser uma das prioridades na educação permanente dos trabalhadores, pois não é apenas uma maneira de prevenção de doenças, mas também, de promoção da saúde ${ }^{(5)}$.

Sabe-se que o profissional de saúde possui uma grande vulnerabilidade em relação ao manejo destes instrumentos de trabalho e aos riscos ocasionados para si próprios, para o paciente, e para o meio ambiente. Nesse sentido, o manejo inadequado dos resíduos pode influenciar toda uma cadeia de possíveis eventos.

A partir deste contexto, emergiu a seguinte questão norteadora: qual é a associação existente entre a exposição de profissionais de saúde à material biológico e os acidentes com instrumentos perfurocortantes, segundo a literatura nacional?

Assim, o estudo teve como objetivo relacionar o manuseio e o descarte de material perfurocortante com os acidentes com material biológico, de acordo com a literatura científica nacional.

\section{MÉTODO}

Trata-se de uma pesquisa qualitativa, do tipo revisão integrativa da literatura, cujo método permite realizar uma síntese sobre o conhecimento em determinado assunto, unificando-a posteriormente à prática. Para isso, é essencial que sejam percorridos alguns passos metodológicos.

Primeiramente realizou-se a elaboração da pergunta norteadora descrita anteriormente, que norteou a busca dos estudos incluídos na posterior análise. Na segunda etapa, iniciou-se a busca na literatura, com pesquisa em base de dados ${ }^{(6)}$. Neste estudo, utilizou-se a as bases de dados Biblioteca Virtual de Saúde (BVS), a Literatura Latinoamericana e do Caribe em Ciências da Saúde (LILACS), Base de Dados de Enfermagem (BDENF) e 


\section{ARTIGO ORIGINAL}

Literatura Internacional em Ciências da Saúde (MEDLINE).

A coleta de dados na literatura foi construída por meio busca simultânea dos seguintes descritores: "Exposição Ocupacional", "Exposição a Agentes Biológicos", e "Pessoal de Saúde", utilizando-se o operador booleano "AND".

Foram considerados como critérios de inclusão: 1 . Ser artigo científico; 2 . Ter o texto completo disponível na base de dados; 3. Ter sido publicado após 2006, pois foi nesse ano houve a primeira publicação do Plano de Gerenciamento de Resíduos de Serviço de Saúde publicado pelo Ministério da Saúde; 4. Possuir texto completo online; 5. Estar no idioma português. A seleção das publicações foi realizada inicialmente pela leitura dos títulos, seguindo-se pelos resumos, e posteriormente, os textos na íntegra.

$\mathrm{Na}$ terceira etapa da revisão integrativa foi realizada a caracterização dos estudos, utilizandose um instrumento de coleta de dados para que sejam retiradas as informações necessárias ${ }^{(6)}$. Tal instrumento desenvolvido nesta pesquisa para a coleta de dados contemplou as seguintes variáveis: título, ano de publicação, local da pesquisa, tipo de estudo, categoria profissional do autor principal, principais achados e locais do estudo.

$\mathrm{Na}$ quarta etapa foi conduzida a categorização dos estudos de acordo com o agrupamento de sentidos ${ }^{(6)}$. Tal agrupamento se deu por meio da análise de conteúdo na qual não existe a preocupação numérica, e sim a análise do grupo social na qual pertencem os dados coletados ${ }^{7}$.

A quinta etapa abordou a discussão dos resultados, sendo estes interpretados e sintetizados, realizando uma comparação com o referencial teórico ${ }^{(6)}$.

A sexta e última etapa, a apresentação da revisão integrativa, sendo esta ampla e que possa proporcionar informações suficientes para que o leitor possa ter uma avaliação crítica sobre os resultados apresentados ${ }^{(6)}$.

\section{RESULTADOS}

A partir dos descritores, foram encontradas
2.453 produções científicas, sendo que destas apenas 70 contemplaram os critérios de inclusão e exclusão. Diante das produções encontradas, foi realizada a leitura dos títulos e resumos, e posteriormente a leitura exploratória das publicações, selecionando-se apenas aquelas que possuíam relação direta com o objeto de pesquisa. Desta forma, 27 publicações foram analisadas nesta revisão. As demais foram excluídas por causa da inconsistência com o objeto desse estudo. A Figura 1 demonstra o fluxo desta seleção.

Figura 1. Fluxo das produções encontradas.

\begin{tabular}{|c|c|c|c|c|}
\hline $\begin{array}{l}\text { Pesquisa nas } \\
\text { bases de dados } \\
\text { da BVS }\end{array}$ & & \multicolumn{2}{|c|}{$\begin{array}{l}2.453 \\
\text { Artigos }\end{array}$} & \\
\hline $\begin{array}{l}\text { Aplicação dos } \\
\text { critérios de } \\
\text { inclusão }\end{array}$ & $\underset{\text { Artigos publicados na }}{\text { integra: }}$ & $\begin{array}{l}\text { Artigos no idioma } \\
\text { portugués: } 103\end{array}$ & \begin{tabular}{|c|} 
A Articos dentro da \\
restriço temporal: 70
\end{tabular} & 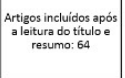 \\
\hline $\begin{array}{l}\text { Total de artigos } \\
\text { selecionados } \\
\text { após a leitura } \\
\text { exploratória }\end{array}$ & & & rtigos & \\
\hline
\end{tabular}

Fonte: dados da pesquisa.

Os estudos selecionados foram classificados e discutidos conforme os seguintes critérios: ano de publicação, local do estudo, categoria profissional do autor principal e, tipo de metodologia. Concomitantemente, foi realizada uma síntese e discussão quanto aos principais resultados obtidos por estes estudos. O Quadro 1 traz a síntese dos principais elementos das publicações analisadas.

Quadro 1. Síntese dos artigos encontrados na Revisão Integrativa.

\begin{tabular}{|c|c|c|c|}
\hline $\begin{array}{c}\text { Título/Local/ } \\
\text { Ano }\end{array}$ & $\begin{array}{c}\text { Categoria } \\
\text { Profissional }\end{array}$ & Método & Periódico \\
\hline $\begin{array}{l}\text { Prevalência de } \\
\text { exposições } \\
\text { ocupacionais } \\
\text { de cirurgiões- } \\
\text { dentistas e } \\
\text { auxiliares de } \\
\text { consultório } \\
\text { dentário } \\
\text { material a } \\
\text { biológico }\end{array}$ & Odontólogo & $\begin{array}{l}\text { Quantita } \\
\text { tivo }\end{array}$ & $\begin{array}{l}\text { Cadernos } \\
\text { de Saúde } \\
\text { Pública }\end{array}$ \\
\hline
\end{tabular}




\section{ARTIGO ORIGINAL}

\begin{tabular}{|c|c|c|c|}
\hline $\begin{array}{l}\text { (Santa } \\
\text { Catarina, } \\
2006)^{(8)}\end{array}$ & & & \\
\hline $\begin{array}{l}\text { Estudo sobre } \\
\text { os acidentes de } \\
\text { trabalho com } \\
\text { exposição aos } \\
\text { líquidos } \\
\text { corporais } \\
\text { humanos em } \\
\text { trabalhadores } \\
\text { da saúde de } \\
\text { um hospital } \\
\text { universitário } \\
\text { (São Paulo, }_{2006)^{9)}}\end{array}$ & Enfermeiro & $\begin{array}{l}\text { Quantita } \\
\text { tivo }\end{array}$ & $\begin{array}{l}\text { Revista } \\
\text { Latino- } \\
\text { Americana } \\
\text { de } \\
\text { Enfermage } \\
\mathrm{m}\end{array}$ \\
\hline $\begin{array}{l}\text { Risco } \\
\text { ocupacional em } \\
\text { unidades de } \\
\text { Suporte Básico } \\
\text { e Avançado de } \\
\text { Vida em } \\
\text { Emergências } \\
\text { (São Paulo, } \\
2006)^{(10)}\end{array}$ & Enfermeiro & $\begin{array}{l}\text { Quantita } \\
\text { tivo }\end{array}$ & $\begin{array}{l}\text { Revista } \\
\text { Brasileira } \\
\text { de } \\
\text { Enfermage } \\
\text { m }\end{array}$ \\
\hline $\begin{array}{l}\text { Enfermeiros } \\
\text { com cargos de } \\
\text { chefia e } \\
\text { medidas } \\
\text { preventivas à } \\
\text { exposição } \\
\text { ocupacional: } \\
\text { facilidades e } \\
\text { barreiras (São } \\
\text { Paulo, 2008) }\end{array}$ & Enfermeiro & $\begin{array}{l}\text { Qualitati } \\
\text { vo }\end{array}$ & $\begin{array}{l}\text { Revista da } \\
\text { Escola de } \\
\text { Enfermage } \\
\mathrm{m} \text { da USP }\end{array}$ \\
\hline $\begin{array}{l}\text { Análise } \\
\text { epidemiológica } \\
\text { dos acidentes } \\
\text { com material } \\
\text { biológico } \\
\text { registrados no } \\
\text { Centro de } \\
\text { Referência em } \\
\text { Saúde do } \\
\text { Trabalhador - } \\
\text { Londrina-PR } \\
\text { (Paraná, 2008) } \\
\text { (12) }\end{array}$ & Enfermeiro & $\begin{array}{l}\text { Quantita } \\
\text { tivo }\end{array}$ & $\begin{array}{l}\text { Revista } \\
\text { Brasileira } \\
\text { de } \\
\text { Epidemiolo } \\
\text { gia }\end{array}$ \\
\hline $\begin{array}{l}\text { Acidentes } \\
\text { ocupacionais } \\
\text { por exposição a } \\
\text { material }\end{array}$ & Enfermeiro & $\begin{array}{l}\text { Quantita } \\
\text { tivo }\end{array}$ & $\begin{array}{l}\text { Revista da } \\
\text { Escola de } \\
\text { Enfermage } \\
\mathrm{m} \text { da USP }\end{array}$ \\
\hline
\end{tabular}

\begin{tabular}{|c|c|c|c|}
\hline $\begin{array}{l}\text { biológico entre } \\
\text { a equipe } \\
\text { multiprofission } \\
\text { al do } \\
\text { atendimento } \\
\text { pré-hospitalar } \\
\text { (Minas Gerais, } \\
2009)^{(13)}\end{array}$ & & & \\
\hline $\begin{array}{l}\text { Exposição } \\
\text { ocupacional } \\
\text { dos } \\
\text { profissionais de } \\
\text { enfermagem } \\
\text { de uma } \\
\text { unidade de } \\
\text { terapia } \\
\text { intensiva } \\
\text { material a } \\
\text { biológico (São } \\
\text { Paulo, 2009) }\end{array}$ & Enfermeiro & $\begin{array}{l}\text { Quantita } \\
\text { tivo }\end{array}$ & $\begin{array}{l}\text { Revista } \\
\text { Eletrônica } \\
\text { de } \\
\text { Enfermage } \\
\text { m }\end{array}$ \\
\hline $\begin{array}{l}\text { Adesão de } \\
\text { profissionais de } \\
\text { enfermagem } \\
\text { ao seguimento } \\
\text { clínico após } \\
\text { exposição } \\
\text { ocupacional } \\
\text { com material } \\
\text { biológico (São } \\
\text { Paulo, 2009) (15) }\end{array}$ & Enfermeiro & $\begin{array}{l}\text { Quantita } \\
\text { tivo }\end{array}$ & $\begin{array}{l}\text { Revista } \\
\text { Eletrônica } \\
\text { de } \\
\text { Enfermage } \\
\text { m }\end{array}$ \\
\hline $\begin{array}{l}\text { Exposição } \\
\text { ocupacional } \\
\text { com material } \\
\text { potencialmente } \\
\text { contaminado } \\
\text { entre } \\
\text { profissionais da } \\
\text { área de apoio } \\
\text { (São Paulo, } \\
\text { 2009) (16) }\end{array}$ & Enfermeiro & $\begin{array}{l}\text { Quantita } \\
\text { tivo }\end{array}$ & $\begin{array}{l}\text { Cogitare } \\
\text { Enfermage } \\
m\end{array}$ \\
\hline $\begin{array}{l}\text { Situações de } \\
\text { risco biológico } \\
\text { presentes na } \\
\text { assistência de } \\
\text { enfermagem } \\
\text { nas unidades } \\
\text { de saúde da } \\
\text { família (USF) } \\
\text { (São Paulo, } \\
2010 \text { ) (17) }\end{array}$ & Enfermeiro & $\begin{array}{l}\text { Quantita } \\
\text { tivo }\end{array}$ & $\begin{array}{l}\text { Revista } \\
\text { Latino- } \\
\text { Americana } \\
\text { de } \\
\text { Enfermage } \\
m\end{array}$ \\
\hline $\begin{array}{l}\text { Acidente com } \\
\text { material }\end{array}$ & Enfermeiro & $\begin{array}{l}\text { Quantita } \\
\text { tivo }\end{array}$ & $\begin{array}{l}\text { Revista } \\
\text { Gaúcha de }\end{array}$ \\
\hline
\end{tabular}




\section{ARTIGO ORIGINAL}

\begin{tabular}{|c|c|c|c|}
\hline $\begin{array}{l}\text { perfurocortant } \\
\text { e entre } \\
\text { profissionais de } \\
\text { enfermagem } \\
\text { de um hospital } \\
\text { universitário } \\
\text { (São Paulo, } \\
2010)^{(18)}\end{array}$ & & & $\begin{array}{l}\text { Enfermage } \\
\mathrm{m}\end{array}$ \\
\hline $\begin{array}{l}\text { Acidentes } \\
\text { registrados no } \\
\text { Centro de } \\
\text { Referência em } \\
\text { Saúde do } \\
\text { Trabalhador de } \\
\text { Ribeirão Preto, } \\
\text { São Paulo (São } \\
\text { Paulo, 2010) } \\
\end{array}$ & Enfermeiro & $\begin{array}{l}\text { Quantita } \\
\text { tivo }\end{array}$ & $\begin{array}{l}\text { Revista } \\
\text { Gaúcha de } \\
\text { Enfermage } \\
\mathrm{m}\end{array}$ \\
\hline $\begin{array}{l}\text { Influência da } \\
\text { exposição } \\
\text { material } \\
\text { biológico na } \\
\text { adesão ao uso } \\
\text { de } \\
\text { equipamentos } \\
\text { de proteção } \\
\text { individual } \\
\text { (Goiás, 2010) } \\
\text { (20) }\end{array}$ & Enfermeiro & $\begin{array}{l}\text { Qualitati } \\
\text { vo }\end{array}$ & $\begin{array}{l}\text { Ciência, } \\
\text { Cuidado e } \\
\text { Saúde }\end{array}$ \\
\hline $\begin{array}{l}\text { A legislação } \\
\text { brasileira e as } \\
\text { recomendaçõe } \\
\text { s internacionais } \\
\text { sobre a } \\
\text { exposição } \\
\text { ocupacional } \\
\text { aos agentes } \\
(\text { São Paulo, } \\
2011)^{(21)}\end{array}$ & Enfermeiro & $\begin{array}{l}\text { Qualitati } \\
\text { vo }\end{array}$ & $\begin{array}{l}\text { Revista } \\
\text { Brasileira } \\
\text { de } \\
\text { Enfermage } \\
\text { m }\end{array}$ \\
\hline $\begin{array}{l}\text { O significado } \\
\text { do acidente de } \\
\text { trabalho com } \\
\text { material } \\
\text { biológico para } \\
\text { os profissionais } \\
\text { de } \\
\text { enfermagem } \\
(\text { São Paulo, } \\
2011)^{(22)}\end{array}$ & Enfermeiro & $\begin{array}{l}\text { Qualitati } \\
\text { vo }\end{array}$ & $\begin{array}{l}\text { Revista } \\
\text { Gaúcha de } \\
\text { Enfermage } \\
m\end{array}$ \\
\hline $\begin{array}{l}\text { Prevenção de } \\
\text { Acidentes com } \\
\text { Material } \\
\text { Biológico entre }\end{array}$ & Enfermeiro & $\begin{array}{l}\text { Quantita } \\
\text { tivo }\end{array}$ & $\begin{array}{l}\text { Revista } \\
\text { Enfermage } \\
\text { m UERJ }\end{array}$ \\
\hline
\end{tabular}

\begin{tabular}{|c|c|c|c|}
\hline $\begin{array}{l}\text { Estudantes de } \\
\text { Enfermagem } \\
\text { (São Paulo, } \\
2011)^{(23)}\end{array}$ & & & \\
\hline $\begin{array}{l}\text { Internação } \\
\text { domiciliar: risco } \\
\text { de exposição } \\
\text { biológica para a } \\
\text { equipe de } \\
\text { saúde (São } \\
\text { Paulo, 2012) }\end{array}$ & Enfermeiro & $\begin{array}{l}\text { Qualitati } \\
\text { vo }\end{array}$ & $\begin{array}{l}\text { Revista da } \\
\text { Escola de } \\
\text { Enfermage } \\
\mathrm{m} \text { da USP }\end{array}$ \\
\hline $\begin{array}{lr}\begin{array}{l}\text { Notificação } \\
\text { acidentes de }\end{array} \\
\text { trabalho com } \\
\text { exposição a } \\
\text { material } \\
\text { biológico: } \\
\text { estudo } \\
\text { transversal } \\
\text { (São Paulo, }_{2012)}{ }^{(25)} \\
\end{array}$ & Enfermeiro & $\begin{array}{l}\text { Quantita } \\
\text { tivo }\end{array}$ & $\begin{array}{l}\text { Online } \\
\text { Brazilian } \\
\text { Journal of } \\
\text { Nursing }\end{array}$ \\
\hline $\begin{array}{l}\text { Risco e } \\
\text { vulnerabilidade } \\
\text { nas práticas } \\
\text { dos } \\
\text { profissionais de } \\
\text { saúde (Santa } \\
\text { Catarina, 2012) } \\
\text { (26) }\end{array}$ & Enfermeiro & $\begin{array}{l}\text { Qualitati } \\
\text { vo }\end{array}$ & $\begin{array}{l}\text { Revista } \\
\text { Gaúcha de } \\
\text { Enfermage } \\
\mathrm{m}\end{array}$ \\
\hline $\begin{array}{l}\text { Representaçõe } \\
\text { s Sociais sobre } \\
\text { as Causas dos } \\
\text { Acidentes com } \\
\text { Materiais } \\
\text { Perfurocortant } \\
\text { es por Técnicos } \\
\text { de } \\
\text { Enfermagem } \\
\text { (Piauí, 2012) }^{(27)}\end{array}$ & Enfermeiro & $\begin{array}{l}\text { Qualitati } \\
\text { vo }\end{array}$ & $\begin{array}{l}\text { Revista } \\
\text { Latino- } \\
\text { Americana } \\
\text { de } \\
\text { Enfermage } \\
\mathrm{m}\end{array}$ \\
\hline $\begin{array}{l}\text { Exposição } \\
\text { ocupacional } \\
\text { por material } \\
\text { biológico no } \\
\text { hospital santa } \\
\text { casa de pelotas } \\
\text { - } 2004 \text { a } 2008 \\
(\text { Paraná, } \\
\left.2012^{(}\right)^{28)}\end{array}$ & Enfermeiro & $\begin{array}{l}\text { Quantita } \\
\text { tivo }\end{array}$ & $\begin{array}{l}\text { Revista } \\
\text { Escola de } \\
\text { Enfermage } \\
\text { m Anna } \\
\text { Nery }\end{array}$ \\
\hline $\begin{array}{l}\text { Atendimento e } \\
\text { seguimento } \\
\text { clínico } \\
\text { especializado }\end{array}$ & Enfermeiro & $\begin{array}{l}\text { Quantita } \\
\text { tivo }\end{array}$ & $\begin{array}{l}\text { Revista da } \\
\text { Escola de } \\
\text { Enfermage } \\
\mathrm{m} \text { da USP }\end{array}$ \\
\hline
\end{tabular}




\section{ARTIGO ORIGINAL}

\begin{tabular}{|c|c|c|c|}
\hline $\begin{array}{l}\text { de profissionais } \\
\text { de } \\
\text { enfermagem } \\
\text { acidentados } \\
\text { com material } \\
\text { biológico (São } \\
\text { Paulo, 2013) }\end{array}$ & & & \\
\hline $\begin{array}{l}\text { Acidente com } \\
\text { material } \\
\text { biológico no } \\
\text { atendimento } \\
\text { pré-hospitalar } \\
\text { móvel: } \\
\text { realidade para } \\
\text { trabalhadores } \\
\text { da saúde e não } \\
\text { saúde (Goiás, } \\
2013)^{(30)}\end{array}$ & Enfermeiro & $\begin{array}{l}\text { Qualitati } \\
\text { vo }\end{array}$ & $\begin{array}{l}\text { Revista } \\
\text { Brasileira } \\
\text { de } \\
\text { Enfermage } \\
\mathrm{m}\end{array}$ \\
\hline $\begin{array}{l}\text { Perfil } \\
\text { epidemiológico } \\
\text { de acidentes } \\
\text { com material } \\
\text { biológico entre } \\
\text { estudantes de } \\
\text { medicina em } \\
\text { um pronto- } \\
\text { socorro } \\
\text { cirúrgico } \\
\text { (Paraná, 2013) } \\
\text { (31) }\end{array}$ & Médico & $\begin{array}{l}\text { Quantita } \\
\text { tivo }\end{array}$ & $\begin{array}{l}\text { Revista do } \\
\text { Colégio } \\
\text { Brasileiro } \\
\text { de } \\
\text { Cirurgiões }\end{array}$ \\
\hline $\begin{array}{l}\text { Caracterização } \\
\text { das exposições } \\
\text { ocupacionais a } \\
\text { material } \\
\text { biológico entre } \\
\text { trabalhadores } \\
\text { de hospitais no } \\
\text { Município de } \\
\text { Teresina, } \\
\text { Estado do } \\
\text { Piauí, Brasil, } \\
\begin{array}{l}\text { 2007 a 2011 } \\
\text { (Piauí, 2013) }^{(32)}\end{array}\end{array}$ & Enfermeiro & $\begin{array}{l}\text { Quantita } \\
\text { tivo }\end{array}$ & $\begin{array}{l}\text { Epidemiolo } \\
\text { gia e } \\
\text { Serviços de } \\
\text { Saúde }\end{array}$ \\
\hline $\begin{array}{l}\text { Consequências } \\
\text { da exposição } \\
\text { ocupacional a } \\
\text { material } \\
\text { biológico entre } \\
\text { trabalhadores } \\
\text { de um hospital } \\
\text { universitário } \\
\text { (São Paulo, }\end{array}$ & Enfermeiro & $\begin{array}{l}\text { Quantita } \\
\text { tivo }\end{array}$ & $\begin{array}{l}\text { Revista } \\
\text { Escola de } \\
\text { Enfermage } \\
\text { m Anna } \\
\text { Nery }\end{array}$ \\
\hline
\end{tabular}

\begin{tabular}{|c|c|c|c|}
\hline 2014$)^{(33)}$ & & & \\
\hline $\begin{array}{l}\text { Seguimento } \\
\text { clínico de } \\
\text { profissionais e } \\
\text { estudantes da } \\
\text { área da saúde } \\
\text { expostos a } \\
\text { material } \\
\text { biológico } \\
\text { potencialmente } \\
\text { contaminado } \\
\text { (São Paulo, } \\
\text { 2015) (34) }\end{array}$ & Enfermeiro & $\begin{array}{l}\text { Quantita } \\
\text { tivo }\end{array}$ & $\begin{array}{l}\text { Revista da } \\
\text { Escola de } \\
\text { Enfermage } \\
\mathrm{m} \text { da USP }\end{array}$ \\
\hline
\end{tabular}

Fonte: dados da pesquisa.

Foram encontradas publicações de todos os anos, exceto 2016 e 2017. O maior quantitativo foi encontrado em 2012, com cinco publicações, seguido por 2010, 2013 e 2009 (quatro publicações), 2011 (três publicações), 2006 e 2008 (duas publicações), 2007, 2014 e 2015 (uma publicação).

$\mathrm{Na}$ classificação conforme a categoria profissional dos autores, identificou-se a enfermagem como categoria autora de $90 \%$ dos artigos analisados, sendo esta a mais representativa, evidenciando um maior quantitativo de produção científica e uma maior preocupação na evolução dos conhecimentos que embasem as suas práticas.

Em relação aos tipos de estudos, identificouse o predomínio do estudo quantitativo (75\%), seguidos dos estudos qualitativos (21\%) e quantiqualitativos (4\%). Estima-se que este predomínio se deu devido às fichas de notificações de acidentes, que geram dados passíveis de serem analisados de maneira estatística e descritiva.

Em relação ao local de publicação, observouse que $60,7 \%$ dos estudos foram realizados na região Sudeste, sendo 16 no Estado de São Paulo e um do Estado de Minas Gerais; $10,7 \%$ na região Centro-Oeste, sendo dois estudos no Estado de Goiás e um do Estado de Mato Grosso do Sul; $21,4 \%$ concentram-se na região Sul, sendo um estudo no estado do Rio Grande do Sul, três no Paraná e dois em Santa Catarina; 7,1\% de pesquisas na região Nordeste, sendo dois estudos no estado de Piauí. Pode ser observada uma lacuna nas produções científicas na região Norte do país. 
Para a análise do conteúdo dos artigos foi realizada a leitura completa das publicações selecionadas com a finalidade de reconhecer e organizar as ideias iniciais. Das leituras, emergiram as Unidades de Significação (US), que foram posteriormente reunidas e agrupadas na criação de categorias, conforme o Quadro 2. As categorias temáticas emergentes foram: "Categoria I Processos inadequados de trabalho"; "Categoria II - Ausência de capacitação técnica dos funcionários".

Quadro 2. Descrição das Unidades de registro de acordo com seus temas centrais e categorias definidas (incluir no quadro a seguir o valor ordinal antes do percentual)

\begin{tabular}{|l|c|l|}
\hline $\begin{array}{l}\text { UNIDADES DE } \\
\text { SIGNIFICAÇÃo }\end{array}$ & $\%$ & CATEGORIAS \\
\cline { 1 - 2 } $\begin{array}{l}\text { Descarte } \\
\text { inadequado }\end{array}$ & 46 & \\
\cline { 1 - 2 } $\begin{array}{l}\text { Inadequação } \\
\text { de ambiente }\end{array}$ & 43 & \multirow{2}{*}{ Processos de trabalho } \\
\cline { 1 - 2 } $\begin{array}{l}\text { Manipulação } \\
\text { de risco }\end{array}$ & 29 inadequados \\
\cline { 1 - 2 } $\begin{array}{l}\text { Reencape ou } \\
\text { desconexão de } \\
\text { agulha }\end{array}$ & 32 & \\
\cline { 1 - 2 } Imprudência & 43 & \\
\cline { 1 - 2 } $\begin{array}{l}\text { Treinamento } \\
\text { inadequado }\end{array}$ & 43 & $\begin{array}{l}\text { Ausência de capacitação } \\
\text { técnica dos funcionários }\end{array}$ \\
\hline
\end{tabular}

Fonte: dados da pesquisa

As unidades de significação que mais se repetiram foram descarte inadequado, imprudência e treinamento inadequado, ou seja, os motivos de exposição a material biológico podem ser reduzidos ao nível mínimo aceitável, pois são fatores que podemos solucionar.

\section{DISCUSSÃO}

Categoria I - Processo de trabalho
inadequado
Embora a literatura deixe explicito que o
descarte de resíduos perfurocortantes seja
exclusivamente em caixas de descarte, os estudos
analisados apontam o processo de trabalho inadequado durante o descarte como o principal causador de exposições. Tal situação pode ser observada através da utilização de locais provisórios ou lixos comuns para o descarte, além do uso acima do limite permitido da caixa coletora (9-24-25-30-34).

Observou-se nos estudos analisados, problemas relacionados ao uso de dispositivos alternativos às caixas coletoras, ao quantitativo inadequado dessas caixas e, quanto a localização destas nos setores, exigindo que o profissional se desloque por longas distâncias com o resíduo, o que pode catalisar acidentes desta natureza ${ }^{(9-10-19-}$ 23-24-26).

Tais situações podem estar associadas a até $55 \%$ dos acidentes com perfurocortantes dentro das unidades e geram riscos não apenas aos profissionais de saúde, mas também a toda a rede de trabalhadores atuantes no gerenciamento dos resíduos, como os profissionais de serviços gerais $^{(12-16)}$.

A falta de adesão a precauções padrão também foi relatada nos artigos analisados, bem como o reencape e a desconexão de agulhas após os procedimentos ${ }^{(13-17-19-21-24-25-28-32)}$.

A proteção à saúde e segurança dos trabalhadores nos estabelecimentos prestadores de serviços de saúde em geral deve ser considerada relevante para o cumprimento das metas estabelecidas no PGRSS. Além das condições adequadas, é necessário informar o trabalhador sobre a análise específica de riscos de resíduos de serviços de saúde. A partir da identificação dos riscos, são elencadas medidas de controle que possuem algumas "linhas de conduta" para proteção coletiva, organização do trabalho, proteção individual e treinamento ${ }^{(4)}$.

Neste sentido, os materiais perfurocortantes devem ser descartados separadamente, no local de sua geração, imediatamente após o uso ou necessidade de descarte, em recipientes rígidos, resistentes à punctura, ruptura e vazamento, com tampa, e devidamente identificados. Devem atender aos parâmetros referenciados em normas específicas, sendo expressamente proibido o esvaziamento desses recipientes para o seu reaproveitamento. As agulhas descartáveis devem 
ser desprezadas juntamente com as seringas, quando descartáveis, sendo proibido reencapá-las ou proceder a sua retirada manualmente ${ }^{(2)}$.

Ainda que tenhamos diversos manuais e estudos em relação à biossegurança e boas práticas, ainda falta aos profissionais a sensibilização necessária para colocá-las integralmente em prática. Além disso, as instituições devem cumprir as normas de segurança, fornecendo uma infraestrutura adequada para atividades e dispositivos de segurança.

Também foi observado como causa de exposição a material biológico, a inadequação do ambiente, como má iluminação, processos equivocados e longa carga horária de trabalho ${ }^{(11-14-}$ 20-25-31).

A manipulação também foi observada como uma das principais fontes de acidentes e contaminações. Esta ocorre a partir da transferência de material biológico de seringas para frascos de exame, e o uso inadequado de $\mathrm{EPI}^{(24-26-18)}$. Segundo o Ministério da Saúde ${ }^{(35)}$, são necessários requisitos mínimos necessários ao trabalho seguro com agentes biológicos e materiais biológicos potencialmente patogênicos, denominados contenção. O termo contenção é usado para descrever os procedimentos de biossegurança utilizados na manipulação de agentes biológicos de acordo com a sua classificação de risco. O objetivo da contenção é prevenir, reduzir ou eliminar a exposição de profissionais, dos usuários do sistema de saúde, da população em geral e do ambiente aos agentes potencialmente perigosos.

A contenção se dá em dois níveis principais, contenção primária e contenção secundária. A contenção primária refere-se à proteção dos profissionais e dos usuários contra a exposição aos agentes de risco, geralmente alcançada pelo uso de equipamentos de proteção individual apropriados, pela implementação das Boas Práticas de Laboratório (BPL), além de incluir a imunização como fator de proteção. Já a contenção secundária consiste na proteção do ambiente contra a exposição aos agentes de risco. Assim, esse nível de contenção inclui a adoção de medidas e práticas relacionadas: a) à proteção individual; b) ao uso de equipamentos de segurança individual ou coletivos; c) à adoção de técnicas e práticas de trabalho em conformidade com a classe de risco do agente manipulado, d) à adequação das instalações e da infraestrutura do local de trabalho ${ }^{(35)}$.

Espera-se que todos os profissionais de saúde tenham conhecimento das medidas de biossegurança, entretanto, por diversos motivos, esses acabam não realizando suas práticas corretamente e isto aumenta o número de casos de exposição à material biológico e risco de contaminação. Nesse sentido, a manipulação de risco é uma das causas mais significativas da exposição à material biológico.

Não obstante a isso, a imprudência é uma prática presente em $43 \%$ dos estudos analisados e, neste sentido, pode-se afirmar que a autoconfiança e o sentimento de que o acidente só acontece com "outros" é o que conduz estes profissionais ao erro. A exemplo disso, verificou-se como causas de acidentes: o excesso de confiança, a falta de atenção e a falta de cuidado ${ }^{\text {(14-22-23 27-33). }}$.

Categoria II - Ausência de capacitação técnica dos funcionários

Segundo o Ministério da Saúde ${ }^{(4)}$, os treinamentos em saúde e segurança dos trabalhadores está embasado em três etapas fundamentais de análise de riscos: 1. Reconhecimento dos riscos existentes no processo de trabalho; 2. Estudo e análise da conjuntura existente, inclusive definindo pontos críticos de controle; 3. Controle dos riscos existentes. O cumprimento da sequência das duas primeiras etapas é importante para se atingir, da melhor forma possível, o principal objetivo, que é "o controle dos riscos existentes". Dentro da análise de riscos, são especificadas prioridades para os níveis de intervenção das medidas de controle: 1a prioridade: eliminação da fonte poluidora (ou contaminante); 2a prioridade: controle de risco na fonte geradora (proteção coletiva); 3a prioridade: controle do risco no meio, entre a fonte e os indivíduos (proteção coletiva); 4ạ prioridade: controle do risco a que está exposto o indivíduo diretamente envolvido (proteção individual).

Neste sentido, observou-se que em $43 \%$ dos 


\section{ARTIGO ORIGINAL}

artigos pesquisados, a falta de treinamento e capacitação foi apontada como um dos principais motivos a acidente de trabalho com perfurocortantes, propiciando assim, a possível exposição a material biológico(8-9-15-18-23-26-31).

Cabe ao empregador prover a qualificação necessária para os trabalhadores envolvidos no gerenciamento de resíduos, desde a sua geração até a coleta deste material. Assim, observou-se que em estudos comparativos, após o treinamento adequado, houve um declínio significativo do quantitativo de acidentes ${ }^{\text {(29-33). }}$

Os gestores das unidades de saúde devem implementar processos de qualificação para os funcionários que fazem parte do processo de segregação do resíduo, em qualquer etapa. 0 empregador deve manter os documentos comprobatórios da realização do treinamento que informem a carga horária, o conteúdo ministrado, o nome e a formação profissional do instrutor, e os trabalhadores envolvidos. Além de levantar cursos, treinamentos e campanhas voltados a todos os envolvidos no gerenciamento, bem como suas frequências, onde o foco é a questão ambiental ${ }^{(4)}$.

\section{CONCLUSÃO}

A presente revisão evidenciou que fatores relacionados aos indivíduos, ao trabalho e à própria instituição têm associação com a adesão dos trabalhadores da saúde ao manuseio e descarte correto de RSS. Esses fatores atuam tanto isoladamente como articulados entre si, influenciando grandemente o processo de trabalho do profissional de saúde, no qual se faz essencial examinar esses fatores em diferentes realidades.

A qualificação dos trabalhadores foi apontada como necessária para a incorporação de práticas seguras nas instituições de saúde. Além disso, outras medidas relacionadas ao ambiente e à organização do trabalho são importantes quando se pretende alcançar uma cultura de segurança organizacional. Essas medidas incluem: melhorias na estrutura física, disposição adequada dos EPI, supervisão das práticas seguras, entre outras. Não se pode pensar em ações voltadas exclusivamente aos indivíduos, sem considerar o contexto e os múltiplos fatores que interferem nesses comportamentos.

Em contexto individual, as práticas inseguras como o reencape de agulhas apontam uma impregnação negativa na cultura profissional, assim só com um intenso trabalho de capacitação seria possível reverter este quadro. Os estudos que relatam que, com o treinamento adequado, é possível promover práticas seguras de biossegurança, diminuindo os índices de acidentes por exposição à material biológico.

A literatura analisada aponta para necessidade do compartilhamento de responsabilidades entre os trabalhadores e os serviços de saúde. Os serviços devem oferecer as condições para a execução de práticas seguras. E os trabalhadores precisam firmar o compromisso ético, reconhecendo o risco a que estão expostos e tomando as medidas preconizadas para minimizar a ocorrência de exposição ocupacional.

\section{REFERÊNCIAS}

1. Bento DG, Costa R, Luz JH, Klock P. Waste management of healthcare services from the perspective of nursing professionals. Textocontexto - enferm. [online]. 2017 [acesso em $07 \mathrm{dez}$ 2017]; 26(1): e6680015. Disponível em: http://www.scielo.br/scielo.php?script=sci_arttext \&pid=S0104-07072017000100313\&lng=en.

2. Ministério da Saúde (BR). Agência Nacional de Vigilância Sanitária. Resolução ANVISA no 306, de 07 de dezembro de 2004. Dispõe sobre o Regulamento Técnico para o gerenciamento de resíduos de serviços de saúde. 2004. Brasília (DF): 2004.

3. Mendes W, Figueiredo M, Salmito M, Araújo $E$, Araújo T, Andrade E. Knowledge and practice of workers, professionals and managers on waste of health services. Rev. pesqui. cuid. fundam. [Internet]. 2015 [acesso em $07 \mathrm{dez}$ 2017]; 7(4): 3216-26. Disponível em: http://www.seer.unirio.br/index.php/cuidadof undamental/article/view/3684. 


\section{ARTIGO ORIGINAL}

4. Ministério da Saúde (BR). Agência Nacional de Vigilância Sanitária. Manual de gerenciamento de resíduos de serviços de saúde. Brasília (DF): 2006.

5. Oliveira JS, Nery AA, Morais RSGL, Robazzi MLCC. Acidente com perfurocortantes entre trabalhadores da saúde. Rev. APS. [online]. 2015 [acesso em 07 dez 2017]; 18(1):108-15. Disponível em:

https://aps.ufjf.emnuvens.com.br/aps/article/view /2392/866.

6. Souza MT, Silva MD, Carvalho R. Revisão integrativa: o que é e como fazer. Einstein. [online]. 2010 [acesso em 07 dez 2017];8(1): 102-6. Disponível em: http://www.scielo.br/pdf/eins/v8n1/pt_1679-

4508-eins-8-1-0102.pdf.

7. Castelo Branco PC. Diálogo entre análise de conteúdo e método fenomenológico empírico: percursos históricos e metodológicos. Rev. abordagem gestalt. [online]. 2014 [acesso em 07 dez 2017]; 20(2): 189-97. Disponível em: http://pepsic.bvsalud.org/pdf/rag/v20n2/v20n2a06 .pdf

8. Garcia, LP, Blank VLG. Prevalência de exposições ocupacionais de cirurgiões-dentistas e auxiliares de consultório dentário a material biológico. Cad. Saúde Pública [online]. 2006 [acesso em $07 \mathrm{dez}$ 2017]; 22(1): 97-108. Disponível em: http://dx.doi.org/10.1590/\$0102-

311X2006000100011.

9. Balsamo AC, Felli VEA. Estudo sobre os acidentes de trabalho com exposição aos líquidos corporais humanos em trabalhadores da saúde de um hospital universitário. Rev. Latino-Am. Enfermagem [online]. 2006 [acesso em $07 \mathrm{dez}$ 2017]; 14(3): 34653. Disponível em: http://dx.doi.org/10.1590/S010411692006000300007.

10. Zapparoli AS, Marziale MHP. Risco ocupacional em unidades de Suporte Básico e Avançado de Vida em Emergências. Rev. bras. enferm. [online]. 2006 [acesso em 07 dez 2017]; 59(1): 41-6. Disponível em: $\quad$ http://dx.doi.org/10.1590/S003471672006000100008 .

11. Malaguti SE, Hayashida M, Canini SRMS, Gir E. Enfermeiros com cargos de chefia e medidas preventivas à exposição ocupacional: facilidades e barreiras. Rev. esc. enferm. USP [online]. 2008 [acesso em 07 dez 2017]; 42(3): 496-503. Disponível em: http://dx.doi.org/10.1590/S008062342008000300012.

12. Spagnuolo RS, Baldo RCS, Guerrini IA. Análise epidemiológica dos acidentes com material biológico registrados no Centro de Referência em Saúde do Trabalhador - Londrina-PR. Rev. bras. epidemiol. [online]. 2008 [acesso em 07 dez 2017]; 11(2): 315-23. Disponível em: http://www.scielo.br/scielo.php?script=sci_arttext \&pid=S1415-790X2008000200013.

13. Oliveira AC, Lopes ACS, Paiva MHRS. Acidentes ocupacionais por exposição a material biológico entre a equipe multiprofissional do atendimento pré-hospitalar. Rev. esc. enferm. USP [online]. 2009 [acesso em 07 dez 2017]; 43(3): 677-83. Disponível em: $\quad$ http://dx.doi.org/10.1590/S008062342009000300025 .

14. Bonini AM, Zeviani CP, Canini SRMS. Exposição ocupacional dos profissionais de enfermagem de uma unidade de terapia intensiva a material biológico. Rev. Eletr. Enf. [online]. 2009 [acesso em 07 dez 2017]; 11(3):658-. Disponível em: http://www.fen.ufg.br/revista/v11/n3/v11n3a25.h tm.

15. Loureiro LA, Gomes AC, Malaguti SE, Canini SRMS, Machado AA, Gir E. Adesão de profissionais de enfermagem ao seguimento clínico após exposição ocupacional com material biológico. Rev. Eletr. Enf. [online]. 2009 [acesso em 07 dez 2017]; 11(2):303-8. Disponível em: http://www.fen.ufg.br/revista/v11/n2/v11n2a10.h tm.

16. Morais NO, Paniago AMM, Negri AC, Oliveira 


\section{ARTIGO ORIGINAL}

OA, Cunha RV, Oliveira SMVL. Exposição ocupacional com material potencialmente contaminado entre profissionais da área de apoio. Cogitare enferm. [online]. 2009 [acesso em $07 \mathrm{dez}$ 2017]; 14 (4): 709-13. Disponível em: http://www.revenf.bvs.br/scielo.php?script=sci_art text\&pid=S1414-85362009000400015\&lng=es.

17. Cardoso ACM, Figueiredo RM. Biological risk in nursing care provided in family health units. Rev. Latino-Am. Enfermagem [online]. 2010 [acesso em 07 dez 2017]; 18(3): 368-72. Disponível em: http://dx.doi.org/10.1590/S0104-

11692010000300011.

18. Silva TR, Rocha AS, Ayres JA, Juliani CMCM. Acidente com material perfurocortante entre profissionais de enfermagem de um hospital universitário. Rev. Gaúcha Enferm. [online]. 2010 [acesso em 07 dez 2017]; 31(4): 615-22. Disponível em: $\quad$ http://dx.doi.org/10.1590/S198314472010000400002.

19. Chiodi MB, Marziale MHP, Mondadori RM, Robazzi MLCC. Acidentes registrados no Centro de Referência em Saúde do Trabalhador de Ribeirão Preto, São Paulo. Rev. Gaúcha Enferm. [online]. 2010 [acesso em 07 dez 2017]; 31 (2): 211-17. Disponível em: http://dx.doi.org/10.1590/S198314472010000200002.

20. Ribeiro LCM, Tipple AFV, Medeiros M, Munari DB, Neves HCC, Souza ACS. Influência da exposição a material biológico na adesão ao uso de equipamentos de proteção individual. Rev. Ciênc. cuid. Saúde [online]. 2010 [acesso em 07 dez 2017]; 9(2): 325-32. Disponível em:http://periodicos.uem.br/ojs/index.php/CiencC uidSaude/article/view/8282/6083.

21. Galon T, Marziale MHP, Souza WL. A legislação brasileira e as recomendações internacionais sobre a exposição ocupacional aos agentes. Rev. bras. enferm. [online]. 2011 [acesso em $07 \mathrm{dez}$ 2017]; 64(1): 160-7. Disponível em: http://dx.doi.org/10.1590/\$0034-

71672011000100023.
22. Magagnini MAM, Rocha AS, Ayres JA. O significado do acidente de trabalho com material biológico para os profissionais de enfermagem. Rev. Gaúcha Enferm. [online]. 2011 [acesso em 07 dez 2017]; 32(2): 302-8. Disponível em: http://dx.doi.org/10.1590/S1983-

14472011000200013.

23. Canalli RTC, Moriya TM, Hayashida M. Prevenção de acidentes com material biológico entre estudantes de enfermagem. Rev. enferm UERJ [online]. 2011 [acesso em $07 \mathrm{dez}$ 2017]; 19(1): 100-6. Disponível em: http://www.facenf.uerj.br/v19n1/v19n1a17.pdf.

24. Figueiredo RM, Maroldi MAC. Internação domiciliar: risco de exposição biológica para a equipe de saúde. Rev. esc. enferm. USP [online]. 2012 [acesso em 07 dez 2017]; 46(1): 145-50. Disponível em: http://dx.doi.org/10.1590/S008062342012000100020.

25. Marziale MHP, Valim MD. Notificação de acidentes do trabalho com exposição a material biológico: estudo transversal. Online braz. j. nurs. [online]. 2012 [acesso em $07 \mathrm{dez}$ 2017]; 11(1). Disponível em: http://www.objnursing.uff.br/index.php/nursing/ar ticle/view/3537/html.

26. Santos, JLG, Vieira M, Assuiti LFC, Gomes D, Meirelles BHS, Santos SMA. Risco e vulnerabilidade nas práticas dos profissionais de saúde. Rev. Gaúcha Enferm. [online]. 2012 [acesso em $07 \mathrm{dez}$ 2017]; 33(2): 205-12. Disponível em: http://www.scielo.br/pdf/rgenf/v33n2/28.pdf.

27. Lubenow JAM, Moura MEB, Nunes BMVT, Figueiredo MLF, Sales LC. Representações sociais sobre as causas dos acidentes com materiais perfurocortantes por técnicos de enfermagem. Rev. RENE [online]. 2012 [acesso em $07 \mathrm{dez}$ 2017]; 13(5): 1132-41. Disponível em: http://www.scielo.br/pdf/rlae/v20n6/pt_21.pdf.

28. Lima LM, Oliveira CC, Rodrigues KMR. Exposição 


\section{ARTIGO ORIGINAL}

ocupacional por material biológico no hospital Santa Casa de pelotas - 2004 A 2008. Esc. Anna Nery Rev. Enferm [online]. 2011 [acesso em $07 \mathrm{dez}$ 2017]; 15(1): 96-102. Disponível em: http://www.scielo.br/pdf/ean/v15n1/14.pdf.

29. Pimenta FR, Ferreira MD, Gir E, Hayashida M, Canini SRMS. Atendimento e seguimento clínico especializado de profissionais de enfermagem acidentados com material biológico. Rev. esc. enferm. USP [online]. 2013 [acesso em $07 \mathrm{dez}$ 2017]; 47(1): 198-204. Disponível em: http://dx.doi.org/10.1590/S0080-

62342013000100025.

30. Tipple ACFV, Silva EAC, Teles SA, Mendonça KM, Souza ACS, Melo DS. Acidente com material biológico no atendimento pré-hospitalar móvel: realidade para trabalhadores da saúde e não saúde. Rev. bras. enferm. [online]. 2013 [acesso em $07 \mathrm{dez}$ 2017]; 66(3): 378-84. Disponível em: http://dx.doi.org/10.1590/S0034-

71672013000300012.

31. Reis PGTA, Driessen AL, Costa ACBA, Nasr A, Collaço IA, Tomasich FDS. Perfil epidemiológico de acidentes com material biológico entre estudantes de medicina em um pronto-socorro cirúrgico. Rev. Col. Bras. Cir. [online]. 2013 [acesso em $07 \mathrm{dez}$ 2017]; 40(4): 287-92. Disponível em: http://dx.doi.org/10.1590/S010069912013000400006.

32. Santos SS, Costa NA, Mascarenhas MDM. Caracterização das exposições ocupacionais a material biológico entre trabalhadores de hospitais no Município de Teresina, Estado do Piauí, Brasil, 2007 a 2011. Epidemiol. Serv. Saúde [online]. 2013 [acesso em 07 dez 2017]; 22(1): 165-70. Disponível em: http://dx.doi.org/10.5123/S167949742013000100017.

33. Marziale MHP, Santos HEC, Cenzi CM, Rocha FLR, Trovó MEM. Consequências da exposição ocupacional a material biológico entre trabalhadores de um hospital universitário. Esc. Anna Nery [online]. 2014 [acesso em 07 dez 2017];
18(1): 11-6. Disponível em: http://dx.doi.org/10.5935/1414-8145.20140002.

34. Almeida MCM, Canini SRMS, Reis RK, Toffano SEM, Pereira FMV, Gir E. Seguimento clínico de profissionais e estudantes da área da saúde expostos a material biológico potencialmente contaminado. Rev. esc. enferm. USP [online]. 2015 [acesso em 07 dez 2017]; 49(2): 259-64. Disponível em: http://dx.doi.org/10.1590/S0080623420150000200011.

35. Ministério da Saúde (BR). Biossegurança em Saúde: prioridades e estratégias de ação Brasília (DF): 2010. 